MUZIKOLOŠKI ZBORNIK - MUSICOLOGICAL ANNUAL XIV, LJUBLJANA 1978

UDK 012 Šturm $?$

\title{
BIBLIOGRAFIJA DEL FRANCA ŠTURMA
}

Katarina B e din a (Ljubljana)

Z glasbo Franca šturma se na koncertnih odrih ne srečujemo, na programu ljubljanske RTV se poredko zvrsti kak samospev ali drobec iz klavirskega opusa, vse preskromno, da bi si mogli ustvariti podobo o umetniški moči in sploh o zvočnem svetu obetavnega odličnjaka Osterčeve, Hábove in Sukove šole.

Spomin na zgodaj umrlega skladatelja je bil prvič obujen ob dvajseti obletnici smrti: nekdanja glasbena šola šiška-Bežigrad si je nadela njegovo ime, RTV pa mu je priredila javno oddajo z naslovom "Večer Francija Šturma». Priložnostno sestavljen komorni spored je bil opremljen z orisom skladateljeve življenjske in umetniške poti. ${ }^{1}$ Odmevnost dogodka, ki je ostal do danes osamljen primer, je zbledela, zato domnevam, da je mimo živeče generacije slovenskih glasbenikov, zlasti učencev Slavka Osterca, malo komu znano več kot to, da je bil šturm neusojeni podaljšek Osterčevega novotarstva in vnet pristaš praškega učitelja Aloisa Hábe, brez morebitne slutnje, da je območje četrttonskega izražanja pripeljal do najvišje kulminacijske točke $v$ bistvu že izumitelj sam. Da šturm ni bil zgolj učenec, kakršnega si more učitelj samo želeti, je mogoče razbrati iz danes večinoma že dostopnih rokopisov. Ti pričajo, da je šturm delal veliko, $\mathrm{z}$ zagonom človeka, ki se je pripisal glasbi iz notranje nuje. Hitro napredovanje $\mathrm{v}$ kompozicijskem znanju je korakoma podrejal vse bolj razvidni kreativni volji, klesanju govorice svojega časa, da bi našel izraz vsemu, kar je $\mathrm{v}$ glasbi iskal. Značilno zanj je, da se je pogosto

${ }^{1} \mathrm{Za}$ prireditev je bil ciklostilno razmnožen spored $\mathrm{s}$ spremnim besedilom: "Večer Francija Šturma (druga javna oddaja iz cikla "Koncerti v Studiju 14"), 13. novembra 1963. . Program: Tri miniature za deco (Jelka Suhadolnik). Sonata da camera za violino in klavir (Slavko Zrimšek, Jelka Suhadolnik). Male skladbe za klavir (Pavel Šivic). Capriccio za violo in klavir (Srečlko Zalokar, Jelka Suhadolnik). Fantazija za violino in klavir (Ali Dermelj, Pavel Šivic). Partizanska romanca, Materi padlega partizana (Bogdana Stritar, Pavel Šivic). Komentar: Borut Loparnik. 
vračal $\mathrm{k}$ začetim glasbenim idejam, vendar med dopolnitvami in različnimi verzijami skladb lahko brez izjeme izluščimo, da je to počel z izostrenim občutkom, da suvereno obvladanje glasbene pismenosti še ni glasbena resnica.

Pretežni del zapuščine Franca Sturma je danes v glasbeni zbirki NUK v Ljubljani. Rokopisi so dobro ohranjeni, po zaslugi članov Sturmove družine je pogrešanih partitur razmeroma malo, ker so po vojni poskrbeli za to, da so izsledili precej notnega gradiva, raztresenega med umetnikovimi prijatelji, največ interpreti. $\mathbf{S}$ prav takšno skrbjo so očuvali in prepustili glasbeni zbirki NUK dva zajetna svežnja skladateljevih osnutkov, posameznih listov in beležk, kar bo imelo poseben pomen pri analitičnem preučevanju Sturmove umetnosti in razvojnega zorenja.

Do danes dostopna ali znana Šturmova zapuščina ima $\mathrm{v}$ bibliografskem pomenu še vrsto odprtih vprašanj. Iz korespondence je razvidno, da je pisal oz. napisal še vse, kar je $\mathrm{v}$ tem prispevku zajeto pod "Pogrešana dela». O njegovi scenski skladbi ni bilo mogoče povedati več kot naslove. V pregledu del tudi zasledimo, da je Šturm začel pri Hábi opremljati svoje skladbe s številkami opusa, vendar sta znana samo op. 2 in 3.

Skladbe $\mathrm{v}$ tem prispevku so razporejene $\mathrm{v}$ kronološkem zaporedju po zvrsteh. Podatki, ki slede naslovu in ev. stavkom, so povzeti iz rokopisov; ce so navedeni v oklepaju, pomeni, da so znani iz drugih virov. Nahajališče rokopisov navajam $\mathbf{v}$ opombah, razen za vse enote, ki so zbrane $\mathbf{v}$ NUK. Pri redkih skladbah, ki so doslej izšle $\mathrm{v}$ tisku, je naveden tudi ta podatek.

\section{ORKESTRSKA GLASBA}

1. SCHERZO (za simfonični orkester). (Grave-Allegro-Grave-Allegro assai). Ljubljana 1931. Rokopis.

\section{2. [TRIJE SIMFONIC̆NI STAVKI]:}

I. Moderato. Brez letnice. Rokopis.

II. Andante. Kamnik, julija 1932. Rokopis. ${ }^{3}$

III. Presto. Kamnik, julija 1932. Rokopis.

3. FANTAZIJA za orkester in moški zbor. (Allegro-Moderato serioso-Allegro moderato). Nedokončana skladba, brez zborovskega parta ali besedila zanj s pripisom: "Končal instrumentirati zaradi Sukove smrti v sredo, 29. maja 1935«. Rokopis.

${ }^{2}$ Skladateljeva sestra Vida Sturm je leta 1971 odstopila vse gradivo, ki ga je imela družina; leto pozneje je tudi glasbeni arhiv RTV Ljubljana dal isti zbirki rokopise, ki so jih uporabljali izvajalci posnetkov.

${ }^{3} \mathrm{~V}$ rokopisu imata drugi in tretji stavek skupno naslovno stran "Andante e Prestou, kjer ima Presto na vrhu prve strani oznako III. Ker ima Moderato oznako I, smemo sklepati, da gre za tri stavke večje ciklične oblike. 


\section{KOMORNA GLASBA}

a) Instrumentalna

1. CONCERTINO za klavir, dve oboi, angl. rog,- dva klarineta, basovsiki klarinet in tri viole. Posvečen Marijanu Lipovšku. 1. Allegro. 2. Vivace. 3. Presto. Ljubljana, 1932. Rokopis.

2. CONCERTINO za flavto, klarinet, oboo in fagot. 1. Allegro. 2. Andante. 3. Con moto. Ljubljana, 1931. Rokopis.

3. GODALNI KVARTET. 1. Moderato. 2. Vivace. 3. Sostenuto. Brez datuma. Rokopis. ${ }^{4}$

4. GODALNI KVARTET. 1. Allegro (Più moderato). 2. Moderato cantabile. 3. Scherzo (Allegretto-Trio-Scherzo D.C.Fine senza repetizioni). 4 Finale (Vivace). Ljubljana, februar 1931. Rokopis.

5. GODALNI KVARTET. 1. Adagio. 2. Allegro appassionato. 3. Moderato. 4. Allegretto. Praga 1935 - Ljubljana 1936. Rokopis.

6. GODALNI KVARTET. 1. Grave. 2. Allegro appassionato. 3. Moderato molto. 4. Allegro risoluto. Praga 1935 - Pariz 1940. Rokopis.

7. GODALNI TRIO. 1. Preludio (Allegro moderato). 2. Passacaglia (Adagio - Poco più vivo - Adagio). 3. Fughetta (Vivace). Ljubljana, 1930. Rokopis.

8. SONATA DA CAMERA za violino in klavir. Posv. Francki Ornikovi. 1. Lento. 2. Allegro. 3. Andante. 4. Vivace. Ljubljana, april 1932. Rokopis.

9. FANTAZIJA za violino in klavir. 1932-1940.5

10. FANTASIE NOCTURNE pour saxofon alto e piano. Nedokončana skladba. 1. Largo (dokončan). 2. Variations (Joyeux, osnutek, 15 taktov). 3. Caprice (osnutek, 8 taktov). Ljubljana, januar 1941. Rokopis.

11. CAPRICE pour alto e piano. $1941 .^{6}$

b) Vokalno-instrumentalna

1. DE PROFUNDIS za sopran, flavto, angl. rog, dva klarineta, basovski klarinet, fagot, rog v F, tubo, šest violin, 4 viole, tri violončela in dva kontrabasa. Besedilo: Alojz Gradnik. Praga, 1935. Rokopis. ${ }^{7}$

2. O BOG, USMILI SE MOJE PRAZNOTE za sopran solo, mešani zbor, dve flavti in violo. Besedilo: Srečko Kosovel. (Andante). Ljubljana, februar 1932. Rokopis.

+ V zapuščini so samo trije stavki, za četrtega, kolikor je bil sploh napisan, nisem našla nobenega podatka.

${ }^{5}$ Rokopis za to skladbo je pogrešan, čeprav je bila izvajana. Gl. op. 1. Navedena je tudi v prijavi del Franca šturma Zavodu za avtorske pravice v Beogradu, 14. aprila 1949. NUK, Šturmova mapa, «Kronika».

- Velja isto, kar je navedeno v op. 5.

7 Rokopis hrani Bogdana Stritarjeva. 


\section{SOLISTIČNA GLASBA}

a) Klavirska

1. [SONATINA] za klavir..$^{1}$. Allegretto. 2. Andante assai sostenuto. 3. Vivace. Ljubljana 1930. Rokopis.

2. FANTAZIJA za klavir, 1. verzija.? Posv. Valensu Vodušku. (ModeratoAllegro non troppo-Tempo I). Ljubljana, maj 1932. Rokopis.

3. SONATA za klavir. 1. Sostenuto. 2. Allegro. 3. Andante. 4. Allegro. Ljubljana, avgust 1932. Rokopis.

4. [SUITA] za klavir. 1. Preludio (Moderato). 2. Fuga (Allegretto). 3. Andante. 4. Passacaglia (Tranquillo). 5. Fuga a 3 temi (Con moto). Ljubljana, september 1932. Rokopis.

5. PET SKLADBIC ZA OTROKE. 1. Alpska pesmica (Moderato). 2. Marš. 3. V cerkvi (Lento). 4. Rumba (Allegro moderato). 5. Konec (Allegretto). Ljubljana, 1932. Rokopis. ${ }^{10}$

6. MALA SUITA za klavir. 1. Preludij (Con moto). 2. Passacaglia (Largo). 3. Andante sostenuto. 4. Fughetta (Moderato). Ljubljana, april 1933. Rokopis.

7. MALE SKLADBE za kiavir. Posv. Marici Vogelnikovi. 1. Moderato. 2. Largo. 3. Vivace. 4. Lento. 5. Allegretto. 6. Molto vivace. Praga, marca 1934. Rokopis.

Izd.: Savez kompozitora Jugoslavije - Društvo slovenskih skladateljev, Ed. št. 68. Ljubljana 1958.

8. SONATINA za klavir. 1. Allegretto. 2. Andante con moto. 3. Vivace. Brez letnice. Rokopis.

9. INTERMEZZO za klavir. (Allegretto cantabile). Ljubljana 1937. Rokopis.

10. SUITA za klavir. 1. Allegro agitato (Più vivo-Vivace). 2. Andante sostenuto. 3. Scherzando, vivace. 4. Largo (Cantabile-Tempo I). 19351939. Rokopis. 11

11. PASTORALE za klavir. (Moderato). Maribor, 6. marca 1939. Rokopis.

12. RHYTME za klavir. (Allegretto). Maribor, 7. marca 1939. Rokopis.

13. BLITZ za klavir. (Con moto). Brez datuma. Rokopis.

14. FANTAZIJA za klavir. (Moderato). Ljubljana, 12. avgusta 1939.

\footnotetext{
${ }^{8}$ Kjer je naslov v oglatem oklepaju, pomeni, da $\mathrm{v}$ izvirniku ni naslova, bodisi da ga avtor ni napisal, bodisi da se naslovna stran ni ohranila. $V$ teh primerih sem se ravnala po oblikovni shemi. skladbe, kjer je bilo to mogoče.

${ }^{9} \mathrm{Na}$ rokopisu je šturm pripisal: "Predelal od 5-12. avgusta 1939«, zato sem to bibliografsko enoto označila kot 1 . verzijo; razlika med obema skladbama opravičuje, da verziji štejem kot samostojni enoti.

${ }^{10}$ Ohranjena sta dva identična rokopisa; enega je hranila Irma Hladnik, drugega vdova Srečka Kumarja.

${ }^{11}$ Verzije iz leta 1935 nisem po virih nikjer zasledila.
} 
15. TRI MINIATURE ZA DECO. Posv. Pavli Kančevi. 1. Allegretto. 2. Andante sostenuto. 3. Vivace. Ljubljana, oktober 1940. Rokopis.

Izd.: Savez kompozitora Jugoslavije - Društvo slovenskih skladateljev, Ed. št. 54. Ljubljana 1958.

b) Violinska

1. SONATA za violino solo. (Allegro). Ljubljana, februar-oktober 1936. Rokopis.

2. FANTAZIJA za violino solo. 1. Moderato. 2. Moderato non troppo. 3. Andante. 4. Lento. Brez letnice. Rokopis.

c) Orgels k a

1. FANTAZiJA za orgle. Posv. Pavletu Rančigaju. 1. Moderato. 2. Allegro. 3. Allegro molto. Praga, februar 1934. Rokopis.

\section{SAMOSPEVI}

1. TRIJE TAGORJEVI ŽRTVENI SPEVI za glas in klavir. 1. To je moja molitev (Allegro moderato). 2. Moj spev je odložil vse lepotičje (Tranquillo). 3. Daj, da se spoje vse pesmi moje mladosti (Vivace). Ljubljana, 19. decembra 1932. Rokopis.

2. [S̆EST VIRGILOVIH PESMI] za glas in klavir. 1. De Patrocli exsequiis (Allegro moderato). 2. De Raptu Proserpinae (Vivace). 3. Deadalus (Sostenuto). 4. Tantalus (Con moto). 5. Nioba (Vivace). 6. Iphigenia (Presto). Kamnik, 6.-11. avgusta 1933. Rokopis.

3. S̆TIRI PESMI na narodne tekste za sopran in klavir. 1. Devojka viče iz tanka grla (Moderato). 2. Sunce žarko, ne sijaš jednako (Grave). 3. Andjelija vodu lila (Vivace). 4. Slavulj pile (Lento). Praga 1934. Rokopis. ${ }^{12}$

4. NAPISI ZA MESECE za glas in klavir. Besedilo: Oton Župančič. Praga 1934. Prepis. ${ }^{13}$

5. PADAJO, PADAJO KAPLJICE za glas in klavir. Besedilo: Oskar Hudales. $1936 .{ }^{14}$

6. [PET KLABUNDOVIH PESMI] za glas in klavir. Besedilo: Alfred Hensche-Klabund. 1. Die ferne Flöte (Moderato). 2. Auf der Wiese (Presto). 3. Silberreicher (Lento). 4. Selbstvergessenheit (Allegretto). 5. Wanderer erwacht in der Herberge (Allegro). Zadnja pesem je nekončana. Brez letnice. Rokopis.

7. ISKAL SEM MOJIH MLADIH DNI za glas in klavir. Besedilo: Oton Župančič. Brez letnice. Rokopis.

8. [DVE LJUDSKI PESMI] za glas in dve kitari. 1. Solnčece moje (Allegretto). 2. Narlejpši roža (Moderato). Brez letnice. Rokopis.

9. DELIBAS̆ za glas in klavir. Besedilo: A. S. Puškin. (Allegro moderato). Ljubljana, januar 1942. Rokopis.

${ }^{12}$ Četrta pesem je ohranjena kot prepis S pisavo, ki ni šturmova.

${ }^{13} \mathrm{~V}$ zapuščini je ohranjen nepopoln prepis skladbe $\mathrm{S}$ pisavo, ki je omenjena v prejšnji op.

${ }^{14}$ Rokopis je izgubljen ali pogrešan, podatek je iz prijave Sturmovih del, ibid. 
10. DAR BREZPLODNI, DAR SLUČAJNI za srednji glas in klavir. Besedilo: A. S. Puškin. Ljubljana 1942. Rokopis.

11. SOLNC̆NA URA za glas in klavir. Besedilo: Alojz Gradnik. Brez letnice. Rokopis.

12. STARKA ZA VASJO za glas in klavir. Besedilo: Srečko Kosovel. (Ljubljana) 1942. Prepis..$^{15}$

13. VESELI, ŽALOSTNI IN C̆ASTITLJIVI KOLEDNIKI za glas in klavir. Besedilo: Oton Župančič. Posv. Nadi Vidmarjevi. 1. Veseli koledniki (Živahno). 2. Žalostni koledniki (Zmerno počasi). 3. Častitljivi koledniki (Počasi). Ljubljana, 9. junija 1943. Rokopis.

14. BORI za glas in klavir. Besedilo: Srečko Kosovel. 2 nedokončana osnutka brez datuma.

15. PARTIZANSKA ROMANCA za glas in klavir. Besedilo: Jože Brejc. Prepis. ${ }^{16}$

Izd.: Umetnost in revolucija - Samospevi 1943-1945, Ljubljana 1971, str. 147-150. Klavirska spremljava: Pavel Šivic. ${ }^{17}$

16. MATERI PADLEGA PARTIZANA za glas in klavir. Izvirnik pogrešan. ${ }^{18}$ Izd.: Umetnost in revolucija - Samospevi 1943-1945. Ljubljana 1971, str. 143-146. Napev zapisal Radoslav Hrovatin, klavirska spremljava: Pavel Šivic.

\section{ZBOROVSKA GLASBA}

a) $\mathrm{Za} \mathrm{mešani} \mathrm{zbor}$

1. PRELEPA JE SELŠKA DOLINA. Priredba ljudske pesmi. Brez letnice. Rokopis.

2. PSALMUS ET HYMNUS. Posv. Srečku Kumarju. ${ }^{19}$ 1. Psalmus (Živahno, veselo). 2. Hymnus (Počasi). Ljubljana, junij 1932. Rokopis.

3. HEJ, BRIGADE. Besedilo: Matej Bor. Izvirnik pogrešan. Izd.: Naša partizanska pesem, Ljubljana 1959, str. $193 .{ }^{20}$

${ }_{15}$ Izvirnika ni v zapuščini (razen dveh nepopolnih osnutkov), skladba je prepisana $\mathrm{s}$ pisavo, omenjena $\mathrm{v}$ op. 12 in 13.

${ }^{16}$ Rokopisni prepis, neznana pisava. Skladba je pisana $v$ As-duru.

${ }_{17}$ Pesem, natisnjena $\mathrm{v}$ tej izdaji je $\mathrm{v}$ B-duru, sicer je identična prepisu iz zapuščine. Urednik zbirke Ciril Cvetko piše v uvodu naslednje: "Šturmova samospeva iz partizanskega obdobja, "Materi padlega partizana" in "Partizanska romanca" sta se ohranila po ustnem izročilu skladateljeve žene Bogdane Stritarjeve, ki je neštetokrat interpretirala predvsem prvo pesem. V smislu njenih sugestij je klavirsko spremljavo k "Materi padlega partizana" oskrbel najprej Ciril Cvetko, nato pa Pavel sivic. Sivičeva je tudi klavirska spremljava $\mathrm{k}$ "Partizanski romanci", ki jo je prvič izvajala Nada Vidmarjevaı (op. 5, XXVIII).

${ }^{18}$ Gl. op. 17.

${ }^{19}$ Besedilo še ni identificirano. Rokopis hrani vdova Srečka Kumarja.

${ }^{20}$ Opombe $\mathrm{k}$ pesmim te zbirke je napisal Radoslav Hrovatin, kjer pojasnjuje, da se sturmov zapis pesmi ni ohranil in da je on 1951 zapisal napev tako, kako mu ga je zapela Bogdana Stritarjeva po spominu (str. 212).

Napev Hej, brigade je po tej izdaji natisnjen še v zbirki Umetnost in revolucija - Zborovske pesmi, Ljubljana 1970, str. 183. 
4. PETINDVAJSET. Besedilo: Karel Destovnik-Kajuh. Rokopis izgubljen. Izd.: Partizanska pesem, Ljubljana $1953 .{ }^{21}$

b) za moški zbor

1. LABOD, RAK IN SČUKA. Besedilo: Ivan Krylov. Posv. Srečku Kumarju. (Allegretto). Ljubljana 1932. Rokopis 22

c) za mladinski $\mathrm{zbor}$

1. TRI OTROKOVE žELJE (za dva glasova). Besedilo: Mile Klopčič. (Pesante). Brez letnice. Rokopis.

2. TRIJE KRALJI (za štiri glasove). Besedilo: Ina Slokanova. Brez letnice. Rokopis.

VI ČETRTTONSKA GLASBA

1. MALA SUITA za dve violini, op. 2. 1. Allegro. 2. Adagio. 3. Andante cantabile. 4. Vivace. Praga, november 1933. Rokopis.

2. LUFTBALONSUITE. Suita za četrttonski klavir, op. 3. 1. Andante. 2. Allegretto. 3. Moderato. 4. Vivace. Praga, april-maj 1934. Rokopis.

3. PET PESMI za glas, violino in violončelo. Besedilo: Oton Župančič. 1. Tak tenka, tak mirna je zarja večerna (Lento, tranquillo). 2. Svež dih od gora (Allegro molto). 3. Tiho prihaja mrak (Andante). 4. Po stranskih potih (Vivace). 5. Palma svetlih sanj (Lento). Rokopis.

4. MALA MUZIKA za dve violini. 1. Agitato. 2. Adagio. 3. Allegretto. 4. Lento. 5. Con moto. Ljubljana 1938. Rokopis.

\section{VII ŠESTINOTONSKA GLASBA}

1. VESELI, ŽALOSTNI IN ČASTITLJIVI KOLEDNIKI (za dva glasova). Besedilo: Oton Župančič. 1. Veseli koledniki (Vivace). 2. Žalostni koledniki (Grave). 3. Castitljivi koledniki (Moderato). Praga, februar 1935. Rokopis.

2. [DVE OTROŠKI IGRI] iz Cicibana Otona Župančiča (za tri glasove). ${ }^{23}$ I. Dedek Samonog. 2. Otroci spuščajo mehurčke. Brez letnice. Rokopis.

${ }_{2 i}$ Iz te pesmarice je bil napev ponatisnjen $\mathrm{v}$ zbirki Umetnost in revolucija Zborovske pesmi, ibid., str. 184-185. V opombi $\mathrm{k}$ tej pesmi piše avtor opomb Radoslav Hrovatin, da je Rado Simoniti "podrobneje stiliziral recitativni del skladbe. Pesem je primerna za izvajanje v zboruu. Ibid., str. 217. Slednjič je Šturmovo zamisel za Kajuhovo pesnitev uporabil še Radovan Gobec za 4-glasni moški zbor "Petindvajset» in ga objavil $\mathrm{v}$ Naših zborih $\mathrm{XXX} / 1978$, št. 1.

${ }^{22}$ Rokopis hrani vdova Srečka Kumarja.

${ }^{23}$ Naslov v izvirniku je "Sstiri otroške igre iz Cicibana Otona zupančiča», napisani sta samo dve.

${ }^{24}$ Rokopisi se niso ohranili, v mapi Šturmovih osnutkov in skic je le nekaj fragmentov. Vprašanje je, če je skladatelj za scensko glasbo sploh izpisoval partiture. Po fragmentih smemo domnievati, da je ta zvrst Sturmove glasbe temeljila na improvizaciji. 
VII SCENSKA GLASBA ${ }^{24}$

1. ČLOVEK - BESEDA - BARVA. Balet. 24. januarja $1938 .{ }^{25}$

2. Glasba h komediji "Večno mlada Saloma» (Meano Cesare). Oktober $1942 .{ }^{26}$

\section{POGREŠANA DELA}

1. Op. 1.27

2. ŠEST MAJHNIH SKLADB za četrttonski klavir. ${ }^{28}$

3. GODALNI KVARTET v četrttonskem sistemu. ${ }^{29}$

4. Skladba za klavir in dvanajst instrumentov. ${ }^{30}$

5. FANTAZIJA za violino in orkester. 31

6. SIMFONIJA.32

7. PIHALNI KVINTET. 33

\section{SUMMARY}

Franc šturm's promising artistic career was already at its beginning abruptly cut short by the World War II. Today he is more generally known only by the opinion that he was to have been the artistic and compositional prolongation of the pursuits of Slavko Osterc and Alois Hába, his two main teachers. From the accessible material and manuscripts it is now possible to establish that at an early stage already sturm had outgrown the academic setting both as regards the volume and the musical value of his compositions.

${ }_{25}$ Letak za predstavo v ljubljanski Operi 24. januarja 1938 najavlja: Franc Šturm: C̆LOVEK-BESEDA-BARVA. Balet. Scen. in kor. Katja Delakova. Kost. A. Černigoj. Gledališki list ni izšel. Gl. Repertoar slovenskih gledališč 1867-1967. Ljubljana 1967, str. 240.

${ }^{26}$ Premiera je bila 3. oktobra 1942 v ljubljanski Drami. Ibid., str. 142.

${ }^{27}$ Verjetno gre za četrttonsko skladbo, ker sta op. 2 in 3 tudi v tem sistemu.

${ }^{28} \mathrm{~V}$ pismu materi z dne 25. 3. 1933 sporoča iz Prage, da je te skladbe končal in da je sena večja $\mathrm{v}$ pripravi«.

${ }_{29}$ 13. 2. 1935 je napisal sestri Vidi: «Hába mi je priznal moj godalni kvartet za absolventsko delow.

${ }^{30} \mathrm{~V}$ pismu sestri Vidi z dne 25. 5. 1936 je sporočil, da piše to skladbo za Nedo (Adrijaničevo, pozneje Kozinovo ženo) in da use z njo muči že cel mesecu.

${ }^{31} \mathrm{~V}$ pismu mami sporoča 25. 3. 1934 iz Prage, da instrumentira fantazijo za violino in orkester.

32 26. 2. 1936 piše materi iz Prage, da komponira simfonijo in da $\mathrm{mu}$ gre dobro spod rok.

${ }^{33}$ Iz Pariza piše materi 31. 12. 1939, da piše pihalni kvintet za Buenos Aires in da bo kmalu gotov. 